\title{
EDITORIAL
}

Revista Prisma Jurídico

v. 20, n. 1, jan./jun. 2021

\author{
v. $20,1, \mathrm{jan} / \mathrm{jun}, 2021$
}

(D) Prof. Dr. José Fernando Vidal de Souza

Editor da Revista Prisma Jurídico

\section{Para citar}

\section{ABNT NBR 6023:2018}

SOUZA, José Fernando Vidal de. Editorial. Prisma Jurídico, São Paulo, v. 20, n. 1, p. 1-3, jan./jun. 2021. http://doi.org/10.5585/prismaj.v20n1.20196.

É com grande satisfação e alegria que apresentamos ao público a edição 01/2021 da Revista Prisma Jurídico, composta de nove artigos. Prisma Jurídico já se firmou como um canal de produção científico-acadêmica, que busca o seu aperfeiçoamento para atingir um estrato de excelência.

Desta maneira, com características de pluralidade e receptividade, Prisma Jurídico recebe contribuições de autores nacionais e estrangeiros, a fim de garantir uma publicação de qualidade.

Para tanto, Prisma Jurídico adota o método double blind peer review, pelo qual cada artigo é avaliado, ao menos por dois pareceristas especialistas na área com elevada titulação acadêmica, bem como são os artigos submetidos a um programa de verificação de similaridade de textos, a fim de se evitar fraudes e todas as modalidades de plágio.

Além disso, busca-se evitar a endogenia e garantir a exogenia, com a efetiva possibilidade de trocas de informações entre as Instituições de Ensino Superior, requisito fundamental para a inserção nas bases indexadoras que emitem fatores de impacto mais elevados, com consequente classificação superior dos periódicos.

Com tais considerações temos que o primeiro artigo de José Ignácio Herce Maza, intitulado Lucha contra la desinformación y libertad de información en internet, riesgos de la intervención de la administración y el procedimiento de actuación contra la desinformación en España discute o controle nocivo da internet, em especial o Despacho PCM/1030/2020 
aprovado pelo Conselho de Segurança Nacional da Espanha que, segundo a autor, coloca em risco a liberdade expressão na Internet.

Na sequência, Jessica Padilha Duarte, Michelle Alves Monteiro e Tatiana de A. F. R. Cardoso Squeff apresentam o artigo Sob um olhar crítico: o acolhimento institucional da criança e do adolescente indígena, que discute o acolhimento institucional de crianças e adolescentes indígenas em situações de risco e vulnerabilidade social, por meio da análise da legislação pátria, apontando a prática de violações e a tentativa de resguardar a cultura indígena no Brasil.

O terceiro artigo, Observação do Direito e das Cidades Inteligentes: contribuições para formação de diretrizes jurídicas para políticas públicas no Brasil, de Fabio Scopel Vanin e Janriê Rodrigues Reck discute as cidades inteligentes, no Brasil e na Espanha, indicando diretrizes jurídicas para produção de políticas públicas nessas localidades.

Depois, Osmar Veronese e Daiane Specht Lemos da Silva nos brindam com o artigo nominado Entre Celas: o encarceramento como sintoma de uma sociedade patológica, um estudo sobre as desigualdades sociais, o crescente aumento da criminalidade, o aprisionamento, a lógica dos condomínios privados, os encarceramentos e as patologias sociais.

Uma análise juseconômica dos desincentivos à prática de insider trading no Brasil, de Daniel Amin Ferraz e Samira Otman se dedica a apreciar a estrutura de desincentivos à prática de insider trading no Brasil, bem como verifica se os mecanismos existentes são suficientes para repelir essa prática diante da Teoria Econômica do Crime.

No sexto artigo, Práticas Colaborativas \& Bioética: a interdisciplinaridade do conflito, Jamile Garcia De Lucca, Maria de Fátima Schumacher Wolkmer e Gustavo Silveira Borges apreciam os avanços materiais e tecnológicos da medicina, o aumento da expectativa de vida e as práticas colaborativas que podem auxiliar na transição dos conflitos de fim de vida, a partir de um diálogo interdisciplinar com a Bioética e seus princípios.

Posteriormente, Luiz Gustavo Tiroli e Rafael Gomiero Pitta apresentam o artigo Negócios Jurídicos Processuais: o controle dos atos processuais pelas partes no sistema processual civil brasileiro, no qual examinam os negócios jurídicos processuais atípicos, previstos no art. 190 do CPC e a influência do princípio da autonomia privada no caráter publicista do processo civil e da axiologia constitucional.

Ato contínuo, em Descompasso na Saúde Pública: a ineficácia do ativismo judicial frente à judicialização da saúde, Beatriz Casagrande Fortunato e Marcos César Botelho discutem a prestação de serviços no âmbito do direito à saúde, bem como a ineficiência e/ou ineficácia das políticas públicas e a intensa judicialização atual desse setor, com desigualdades, 
desproporcionalidades e benesses de alguns demandantes, o que está a exigir que os julgadores necessitam de corpo técnico especializado, tal como a plataforma e-NATJus para prolação de sentenças fundadas em equidade e dotadas de maior precisão, para evitar injustiças.

Finalmente, Valéria Silva Galdino Cardin e Jamille Bernardes da Silveira Oliveira dos Santos apresentam um tema atual e urgente, ou seja, Da Violência de Gênero no contexto da pandemia da Covid-19: um diálogo à luz dos direitos humanos e da personalidade, no qual são examinadas as questões de isolamento social na pandemia da COVID-19 com as orientações da Organização Mundial da Saúde (OMS) e os seus desdobramentos, dentre eles, o crescimento do número de casos de violência contra a mulher, como contraponto aos direitos humanos e da personalidade.

Por derradeiro registramos agradecimentos especiais à Heloísa Correa Meneses, Editora Assistente, pelo empenho em garantir a periodicidade da revista e à nossa Bibliotecária - Editora Técnica, Cristiane dos Santos Monteiro, responsável pela gestão logística e pelo processo de editoração, por sua dedicação e competência.

Com isso, o nosso desejo é que todos tenham uma ótima e prazenteira leitura. 